\title{
Availability of health services vs. health condition of residents of rural areas in Poland - Analysis performed on the basis of EHIS 2009
}

\author{
Iwona Laskowska' \\ 1 Department of Spatial Econometrics, Faculty of Economics and Sociology, University of Lodz, Poland \\ Laskowska I. Availability of health services vs. health condition of residents of rural areas in Poland - Analysis performed on the basis of \\ EHIS 2009. Ann Agric Environ Med. 2015; 22(4): 700-703. doi: 10.5604/12321966.1185779
}

\begin{abstract}
Introduction. One of the aspects considered in a debate preceding the establishment of the new retirement age in Poland, was the health condition of the Polish population. A steady increase in the average life expectancy, observed for several years, is much higher in the cities than in the country. One of the reasons for this might be a limited availability of health services in rural areas.

Objective. The aim of the study is to assess the scale of income-related inequalities in the access to health services in rural areas, and subsequently to assess the impact of having to give up some medical services on the subjective perception of health condition by rural inhabitants.

Materials and methods. Individual data derived from the European Health Interview Survey (EHIS) conducted in 2009 constituted the basis for the presented analysis. The concentration index was used to measure the income-related inequalities in the use of medical services. The ordered logit model was used to verify the hypothesis that the availability of health services has an impact on the health condition.

Results. Significant differences in the distribution of medical services utilization with regard to income, were found only in the case of hospital services. People with low income stay in hospital more often. The obtained inequality indices show a lack of income-related inequality in the use of outpatient services. The performed analyses confirm a negative impact of giving up this type of services on the health condition of residents of rural areas.

Conclusions. The availability of medical services is an important determinant of the health condition. Too few medical institutions and scarce medical personnel limits the use of these services, and not only for people with low income.
\end{abstract}

Key words

health, health services, rural areas, Poland, concentration index

\section{INTRODUCTION}

In June 2012, the Polish Parliament adopted an Act that extended to 67 years the retirement age for men and women in Poland. One of the aspects considered in the debate preceding the establishment of the upper limit of the retirement age was the health condition of Polish society. To assess the fitness of each generation for work, one should not take into account the length of life in general, but rather the length of healthy life. Not only do the Poles live a few years less than people in Western Europe, but their life in good health is also shorter. A large part of society struggles with various diseases. Poland has a high proportion of the disabled, the chronically and permanently ill, and people evaluating their health condition as poor.

The health condition of the population is territorydependent. Despite the overall improvement in the health condition in Poland, the obtained health benefits vary in different regions. A steady increase in the average life expectancy observed for several years is much higher in urban areas than in the rural areas [1].

Various surveys show that only young people in rural areas (up to 39 years of age) rate their health better than their peers

Address for correspondence: Iwona Laskowska, Department of Spatial Econometrics, Faculty of Economics and Sociology, University of Lodz, Rewolucji 1905 r. 37, 90-214 Lodz, Poland

E-mail: ilaskow@uni.lodz.pl

Received: 12 December 2012; accepted: 16 October 2014 living in the city. People aged 40 years and over perceive their health worse than the urban residents [2].

One of the factors determining the health condition is access to health services [3, 4]. Relatively low expenditures on health care in Poland limit the access to health services. This limited availability affects in particular the residents of rural areas, who seek specialist advice less often than urban dwellers. $20 \%$ of them have never been seen by a specialist physician [2].

Another problem, apart from the limited availability of health care services, is caused by disparities in their use by various social groups (isolated on the basis of certain criteria). One of the most often discussed issues related to this matter is income inequality $[5,6,7,8]$. The income-related inequalities refer to differences in the use of health services by persons with various levels of income.

The aim of the presented research is to assess the scale of income-related inequality in accessing health services in rural areas (approximated by their use), and to subsequently assess the impact of having to give up some medical services on the subjective perception of health condition by country dwellers.

Analyses of use of health services in Poland, made with the application of a similar methodology based on data derived from the 'Social Diagnosis' study, have been presented [9]. Firstly, these analyses did not focus exclusively on rural areas. Secondly, on the basis of the possessed data, it was possible to divide the services, depending on the payer, i.e 
services available within the health insurance (paid for by the National Health Fund) and services paid for by the patients on a private basis.

The EHIS data used for the purpose of these analyses provide information about various types of health services. The presented analyses covered hospital stays, advice given by internists and advice given by specialist physicians.

\section{MATERIALS AND METHOD}

Statistical data. Individual data from the European Health Interview Survey (EHIS) constituted the basis of these analyses. This was the first representative survey of the health condition of the Polish population conducted by the Polish Central Statistical Office, in accordance with the Eurostat guidelines. The collected information related to households and individuals composing them. The rural residents constituted $39 \%$ of the respondents [2]. The analyses presented below relate to the rural population aged 15 years and over.

The collected statistical data provided information about the self-assessment of the physical and mental health condition of the population, disability and chronic diseases, as well as about the use of medical services. Micro-econometric studies often consider the use of medical services as an approximation of their availability.

The observation covered the most important forms of health care services: hospital stays (with accommodation and without), visits to general practitioners and visits to specialist physicians. Information can also be found about giving up hospital treatment and visits to doctors. Respondents indicated their need to give up some services by answering the following questions: 'In recent months, did you really need to consult a specialist doctor, but failed to do so?' A similar question was asked about hospital stays: 'In the last 12 months, did your doctor tell you that you needed to be admitted to hospital as a patient, but you were not admitted?'

Research Methodology. To measure income-related inequality in the use of medical services the concentration index $C_{M}$, commonly used in such analyses, was applied:

$$
C_{M}=\frac{2}{\bar{y}} \operatorname{cov}\left(y_{i}, r_{i}\right)
$$

where $y_{i}$ and $r_{i}$ mean respectively a use of health services by the $i$-th individual and its rank (in the form of a fraction) in the distribution of income, $\bar{y}$ is the average use of services among the surveyed respondents in the analysed period [5, $6,7,8]$. The index value remains in the range $[-1,1]$. A value of zero means a lack of socio-economic inequalities in the use of health services. Positive index values indicate a higher value of the analysed variable among persons with a higher socio-economic status, expressed as income. The $C_{M}$ index, also referred to as a non-standardized index, measures the degree of inequality in medical consumption, without taking health needs into account.

A comprehensive analysis of the use of health services covers both an analysis of inequality in the probability of use of health services (probability of visits), as well as disparities in the number of visits [5]. The presented analysis is limited to the inequality in the likelihood of use of selected services. Consumption of services $y_{i}$ is considered as a binary variable which assumes the value of 1 , if the respondent has consulted the family doctor or a specialist physician, or has stayed in hospital in the last 12 months (the value of 0 was applied if the respondent has not used any of these services).

Modification of the concentration index for binary variables is presented in $[9,10]$.

An econometric model, based on the concept of latent variables, was used to verify the hypothesis about the impact of the availability of health services on the health condition. Latent variable - health condition $h^{*}$ is not directly observable. The actual unobservable health condition is represented by a subjective assessment of health condition $h_{i}$. Subjective assessment of health condition of the respondents (self-assessment) is based on the question about their satisfaction with their own health. The following question was asked: 'How do you assess your health in general?' The answers to this question were put on a 5-point scale, from very good to very bad. The $h_{i}$ variable ranges from 1 (poor health condition) to 5 (very good condition). The following transformation of the $h^{\star}$ variable is assumed:

$$
h_{i}=\left\{\begin{array}{l}
1 \text { if }-\infty \leq \mathrm{h}_{\mathrm{i}}^{*}<\tau_{1} \\
2 \text { if } \tau_{1} \leq \mathrm{h}_{\mathrm{i}}^{*}<\tau_{2} \\
3 \text { if } \tau_{2} \leq \mathrm{h}_{\mathrm{i}}^{*}<\tau_{3} \\
4 \text { if } \tau_{3} \leq \mathrm{h}_{\mathrm{i}}^{*}<\infty
\end{array}\right.
$$

$\tau$ indicates the border points associated with a shift from a lower category of the subjective assessment of health condition to a higher one.

If the actual unobservable health condition is represented by a variable expressed on the ordered scale, the model of ordered variables should be used. Probability of assuming by the $h$ variable one of the $m$ categories $(m=1, \ldots, J)$ can be written as follows:

$$
P\left(h_{i}=m \mid \mathbf{x}_{i}, \boldsymbol{\beta}, \boldsymbol{\tau}\right)=F\left(\tau_{m}-\mathbf{x}_{i}^{T} \boldsymbol{\beta}\right)-F\left(\tau_{m-1}-\mathbf{x}_{i}^{T} \boldsymbol{\beta}\right),
$$

where $\mathbf{x}_{i}$ is the vector of explanatory variables, $\boldsymbol{\beta}$ the vector of structural parameters, $F$ is the cumulative distribution function of the probability distribution. Depending on the form of the $F$ cumulative distribution function, one considers the ordered probit model or the ordered logit model. The ordered logit model was used to model the self-assessment of the health condition.

In the estimated models of health condition, the availability of services was approximated by a necessity to give up some types of health services. ${ }^{1}$ This necessity was included in the model with the application of binary variables, assuming the value of 1 if the respondent was forced to give up certain health services, and the value of 0 if this was not the case.

The following variables were recognized as other potential determinants of the health condition [see e.g. [5, 12]:

- incomes: binary variables corresponding to particular classes of income (reference category: highest income);

- education: binary variables denoting the education: higher education, post-secondary and secondary, basic vocational, junior high school and primary (reference category: no education);

1. Due to the possible existence of a two-direction relationship between the health condition and use of medical services, which is connected with the problem of exogeneity of the explanatory variables, the necessity to give up services, instead of their use, was used in the models. 
Table 1. Indices of inequality for the probabilities of use of selected medical services in the past 12 months in 2009

\begin{tabular}{|c|c|c|c|c|c|c|}
\hline \multirow{2}{*}{ Type of service } & \multicolumn{3}{|c|}{ Rural areas } & \multicolumn{3}{|c|}{ Urban areas } \\
\hline & Inequality index $C$ & Standard error & t-statistic & Inequality index $C$ & Standard error & t-statistic \\
\hline Hospital stay & -0.04298 & 0.0213 & -2.0147 & -0.0221 & 0.0170 & -1.2993 \\
\hline Consultations by an internist & -0.0056 & 0.0049 & -1.1425 & 0.0096 & 0.0039 & 2.4630 \\
\hline Consultations by a specialist doctor & 0.0126 & 0.0099 & 1.2609 & 0.0261 & 0.0067 & 3.9198 \\
\hline
\end{tabular}

bold - statistically significant indices

Source: calculated by the author

- age: dummy variables corresponding to specific age groups (reference category: 70 years and over);

- gender: (dummy variable: value 1 for male);

- physical activity: measured by the number of hours spent in the last 7 days on activities requiring physical effort, including a walk lasting at least 10 minutes.

\section{RESULTS}

Table 1 presents non-standardized indices of income-related inequality for the probability of use of selected medical services. The incomes are expressed by a household income per capita. For purposes of comparison, similar indices are given for use of medical services by the urban population.

Negative value of the $C_{M}$ index for the use of hospital services indicates a greater use of these services by persons with lower household income per person. The same applies to seeking internist's advice, but this index is not statistically significant. A low and statistically insignificant value of the $C_{M}$ index for use of specialist services by the rural population should be considered as quite surprising.

Among the urban population, the situation is different. Significant inequalities relate to seeking the advice of internists and specialist doctors. These inequalities are in favour of persons earning a high income.

The index values are not high. As already mentioned, the presented inequality indices are non-standardized, i.e. they do not include health needs. Standardization with regard to the needs often increases the values of the concentration indices. This is connected with higher needs of those who are less affluent.

Table 2 presents results of a health condition model, taking into account the availability of services expressed by the necessity to abandon seeking advice of specialist physicians ${ }^{2}$ (Model 1), or the need to give up hospital treatment (Model 2).

As can be seen from the conducted analyses, the need for giving up medical services clearly reduces the likelihood of a better perception of own health by rural inhabitants. Both the need to abandon hospital treatment and the necessity to give up seeking the advice of specialist physicians, have a statistically significant impact on the self-assessment of own health condition $(\mathrm{p}<0.05)$. Therefore, the thesis about a negative impact of the limited availability of health services is confirmed. All other explanatory variables are statistically significant at the significance level $\mathrm{p}<0.05$ (except for those with junior high school education level, which is significant at the significance level of $\mathrm{p}<0.1$ ).

Males in rural areas assess their health better than women. The analyses confirm existence of a connection between health condition and the level of education and
Table 2. Ordered logistic regression model results: dependent variable - self-assessment of health condition $(N=10,739)$

\begin{tabular}{|c|c|c|c|}
\hline \multirow{2}{*}{\multicolumn{2}{|c|}{ Explanatory variable }} & \multicolumn{2}{|c|}{$\begin{array}{c}\text { Parameter estimate } \\
\text { [p-value }]\end{array}$} \\
\hline & & Model 1 & Model 2 \\
\hline \multicolumn{2}{|c|}{ Giving up advice of a specialist doctor } & -0.8084 & \\
\hline \multicolumn{2}{|c|}{ Giving up hospital treatment } & & $\begin{array}{r}-1.5883 \\
{[0.000]}\end{array}$ \\
\hline \multicolumn{2}{|l|}{ Age $15-29$ years } & $\begin{array}{l}3.9829 \\
{[0.000]}\end{array}$ & $\begin{array}{l}3.9959 \\
{[0.000]}\end{array}$ \\
\hline \multicolumn{2}{|l|}{$30-49$ years } & $\begin{array}{l}2.4763 \\
{[0.000]}\end{array}$ & $\begin{array}{l}2.4774 \\
{[0.000]}\end{array}$ \\
\hline \multicolumn{2}{|l|}{$50-69$ years } & $\begin{array}{l}0.9771 \\
{[0.000]}\end{array}$ & $\begin{array}{l}0.9713 \\
{[0.000]}\end{array}$ \\
\hline \multicolumn{2}{|c|}{ Gender ( 1 in the case of a male) } & $\begin{array}{l}0.2505 \\
{[0.000]}\end{array}$ & $\begin{array}{l}0.2624 \\
{[0.000]}\end{array}$ \\
\hline \multirow{4}{*}{ Income categories } & 1 (lowest income) & $\begin{array}{l}-0.6799 \\
{[0.000]}\end{array}$ & $\begin{array}{l}-0.6872 \\
{[0.000]}\end{array}$ \\
\hline & 2 & $\begin{array}{l}-0.5234 \\
{[0.000]}\end{array}$ & $\begin{array}{l}-0.5067 \\
{[0.000]}\end{array}$ \\
\hline & 3 & $\begin{array}{c}-0.3254 \\
{[0.000]}\end{array}$ & $\begin{array}{c}-0.3205 \\
{[0.000]}\end{array}$ \\
\hline & 4 & $\begin{array}{l}-0.1671 \\
{[0.010]}\end{array}$ & $\begin{array}{l}-0.1560 \\
{[0.016]}\end{array}$ \\
\hline \multirow{4}{*}{ Education } & higher & $\begin{array}{l}0.9638 \\
{[0.000]}\end{array}$ & $\begin{array}{l}1.0086 \\
{[0.000]}\end{array}$ \\
\hline & post-secondary and secondary & $\begin{array}{l}0.4539 \\
{[0.003]}\end{array}$ & $\begin{array}{l}0.4905 \\
{[0.000]}\end{array}$ \\
\hline & basic vocational & $\begin{array}{l}0.3357 \\
{[0.026]}\end{array}$ & $\begin{array}{l}0.3757 \\
{[0.012]}\end{array}$ \\
\hline & junior high school & $\begin{array}{l}0.1868 \\
{[0.101]}\end{array}$ & $\begin{array}{l}0.2268 \\
{[0.096]}\end{array}$ \\
\hline \multicolumn{2}{|l|}{ Physical activity } & $\begin{array}{l}0.0013 \\
{[0.000]}\end{array}$ & $\begin{array}{l}0.0013 \\
{[0.000]}\end{array}$ \\
\hline \multicolumn{2}{|l|}{ Pseudo-R2 } & 0.1958 & 0.1943 \\
\hline
\end{tabular}

Source: calculated by the author.

earned income in rural areas. The probability of a better assessment of health condition among people with low income is significantly lower than among those with the highest income (reference category). Among persons with no education (reference category), the probability of a better assessment of health condition is lower than that by those who are educated. The biggest difference in the health condition, measured with a subjective assessment, can be found between rural inhabitants with no education and those with higher education. 


\section{DISCUSSION}

The first part of this study attempted to assess the scale of income-related inequalities in access to health services in rural areas (approximated by their use). The second part dealt with assessment of the impact of giving up selected health services on health condition. No such analyses have been conducted previously for the rural areas in Poland.

Significant differences in the distribution of the use of medical services because of income were found only in the case of hospital services. People with low incomes stay in hospital more often. Difficult access to specialist outpatient services may result in the need for hospital treatment. No significant differences were found, however, in the distribution of medical advice.

The presented inequality indices are non-standardized, i.e. they do not include health needs; therefore, they cannot be considered in terms of horizontal inequality. Standardization of medical needs, usually approximated by age and health condition, requires estimation of a relevant econometric model explaining the consumption of health services. This will be the subject of further analysis.

\section{CONCLUSIONS}

A good health condition is one of the prerequisites of pursuing professional activity up to 67 years of age by the older production age groups. This is especially important for those engaged in physical labour, which is the main source of income for rural inhabitants. Improvement in the currently unsatisfactory health condition of rural inhabitants requires, apart from improving the working conditions and safety, better access to health care services (especially those that are specialized and highly specialized).

The performed analyses confirm the negative impact of abandoning such services on the health condition of rural residents. At the same time, the obtained inequality indices show a lack of income-related inequality in the use of outpatient services (as opposed to the situation in the cities). Too few medical institutions and scarce medical personnel limits the use of these services, and not only for people with low income.
The research results may be important for the health policy, affecting the allocation of health resources.

\section{Acknowledgements}

The author wishes to express her grateful appreciation for financial assistance by the State Committee for Scientific Research under Project No. N N 111271438.

\section{REFERENCES}

1. Demographic Yearbook of the Central Statistical Office, Warsaw, 2011.

2. Health condition of the Polish population in 2009, the Central Statistical Office, Warsaw, 2011.

3. Folland S, Goodman AC, Stano M. The economics of health and health care. Prentice Hall, New Jersey, 2001.

4. Or Z, Wang J, Jamison D. International differences in the impact of doctors on health: a multilevel analysis of OECD countries. J Health Econ. 2005; 24(3): 531-560.

5. van Doorslaer E, Koolman X, Jones AM. Explaining income-related inequalities in doctor utilization in Europe. Health Econ. 2004; 13(7): 629-647.

6. Bago d'Uva T., Jones A. M., van Doorslaer. Measurement of Horizontal Inequity in Health Care Utilisation using European Panel Data. Tinbergen Institute Discussion Paper TI 2007-059/3, http://repub. eur.nl/res/pub/10453/2007-0593.pdf (access: 2012.04.20).

7. Shin H, Kim J. Differences in income-related inequality andhorizontal inequity in ambulatory care use between rural and non-rural areas: using the1998-2001 U.S. National Health Interview Survey data. Int J Equity Health 2010, 9:17 http://www.equityhealthj.com/content/9/1/17 (access: 2012.07.21)

8. Zhou Z, Gao J, Fox A, Rao K, Xu K, L Xu L, Zhang Y. Measuring the equity of inpatient utilization in Chinese rural areas. BMC Health Serv Res. 2011; 11:201

9. http://www.biomedcentral.com/1472-6963/11/201 (access: 2012.07.21).

10. Laskowska I. Zdrowie i nierówności w zdrowiu - determinanty i implikacje ekonomiczno-społeczne (Health and inequalities in health - determinants and socio-economic implications). Wydawnictwo Uniwersytetu Łódzkiego, Łódź, 2012 (in Polish).

11. O’Donnell O, van Doorslaer E, Wagstaff A, Lindelow M. Analyzing Health Inequalities Using Household Survey Data. The World Bank, Washigton, D.C., 2008.

12. Wagstaff $A$. The bounds of the concentration index when the variable of interest is binary, with an application to immunization inequality. Health Econ. 2005; 14(4): 429-432.

13. Wildman J. Modelling health, income and income inequality: the impact of income inequality on health and health inequality. J Health Econ. 2003; 22(4): pp.521-538. 